\title{
Analysis on the Construction and Operation of the Elderly-care Policy Model in Qingshan District of Wuhan City
}

\author{
Ping Lei \\ School of Literature, Law and Economics \\ Wuhan University of Science and Technology \\ Wuhan, China
}

\author{
Bingfeng Zhang \\ School of Literature, Law and Economics \\ Wuhan University of Science and Technology \\ Wuhan, China
}

\begin{abstract}
A comprehensive aging society is social issue faced by the world. The people's yearning for a better life also includes the sense of security. Wuhan is a large city with a relatively high degree of aging. Qingshan District is one of the urban areas with a relatively high degree of aging in Wuhan. In accordance with the logic of asking questions, analyzing problems, and solving problems, this article is divided into current status, problem analysis and countermeasure research. It starts with the current situation of aging in the Qingshan District, reveals the contradiction among the universality, urgency, and objective reality of providing for the elderly in the aging society. It is problem-oriented, further sorts out current policies, and analyzes and draws on domestic and foreign pension models, and proposes an elderly-care policy system that meets the characteristics of Qingshan District. It has strong pertinence and practicality. The full text is divided into six parts. The first is the status quo of aging in Qingshan District. The second is the situation of old-age care in Qingshan District. The third is the main problems existing in the policy model of elderly-care in Qingshan District. The fourth is the current status of pension policy in Wuhan. Fifth, it is the enlightenment of the elderly-care policy model at home and abroad. The sixth is to speed up the construction of the elderlycare policy model. The author tries hard to draw countermeasure suggestions for the government and relevant departments to study, improve the level of elderly-care services in the region, promote the development of elderly-care, and build happy and harmonious society.
\end{abstract}

Keywords—aging; elderly-care policy; policy model

\section{INTRODUCTION}

Qingshan District is a traditional central and industrial district in Wuhan. If the new round of urbanization construction is an important driving force to accelerate the transformation and development of Qingshan District, the current aging of the population is the historical challenge that Qingshan District needs to face. In the face of an increasingly severe population aging situation, Qingshan District must plan ahead and speed up the development of an old-age care service system to formulate an elderly-care policy model suitable for clothing, food, shelter, transportation, and employment for the elderly in Qingshan district.

\section{Status QuO OF AGING IN QINGSHAN District OF WUHAN}

According to the data analysis of the Statistical Yearbook of Qingshan District from 2012 to 2015, the current situation of aging in Qingshan District presents the following characteristics:

\section{A. The Elderly Population Is Large and the Aging Is Increasingly Serious}

As of 2012, Qingshan District in Wuhan City in the 13 urban areas of the highest level of aging, $21.40 \%$, the elderly more than 90,000, an average of five Qingshan people in the elderly. In the 1950s, hundreds of thousands of young and middle-aged industrial workers gathered in Qingshan to support the construction of Wuhan Iron and Steel Corporation, which objectively formed the centralization of the age distribution of the population in Qingshan District. There were 80,000 retirees in Wuhan Iron and Steel Corporation alone, accounting for $4 / 5$ of the aged population in Qingshan District.

\section{B. The Rate of Aging Is Fast, and the Age Structure of the Population Forms an Inverted Pyramid}

On the one hand, it is the decline in the birth rate. On the other hand, it is the increase in the average life expectancy. And then, ultra-rapid development of the aging emerged. At the end of 2015, there were 111,000 elderly people over the age of 60 years old in Qingshan District, accounting for 21.5 percent of the region's total population. Of these, 44,000 were 60-65 years old. 405,000 were 66-75 years old. 15,000 were $76-80$ years old and 112,000 were over 80 years old.

\section{The Empty-nested Phenomenon Is Increasing}

Nowadays, the family structure is developing towards miniaturization and centralization. With the pressure of job competition, children and parents are usually living separately. And then, there is a large of empty nesters. In 2015, there were 897 isolated elderly people, 3873 disabled elderly people, 3423 empty-nest elderly people, 432 disabled elderly people, and a very high proportion of disabled and 
semi-disabled elderly people. The total is 110000 . According to the sample survey, among 2022 old people, 458 old people were over 70 years old, 52 old people were unable to take care of themselves, 249 old people were semi-take care of themselves, and 578 old people were suffering from various chronic diseases, accounting for $26.9 \%, 3.05 \%$, $14.6 \%$ and $34 \%$ respectively. With the gradual change of the family and population structure, the demand of the elderly for health services, home care services and life care services is increasing day by day.

\section{THE ELDERLY-CARE DEMAND IN QINGSHAN DISTRICT}

\section{A. Analysis on Market Demand}

The old-age pension model can be divided into three categories: family pension, institutional pension and community pension. The content of the old-age pension mainly includes three aspects: economic support, life care and spiritual comfort. Market demand is embodied in two aspects: institutional pension service and community pension service.

1) There is a need for pension institutions: According to the statistics, there are 15 pension institutions in the region, including one state-run institution, 14 private institutions. There are 1,900 beds for the elderly. And more than 1,300 elderly people are in these pension institutions. According to the national standard of 30 beds for every 1,000 old people, there is a shortage of more than 1,100 beds in the region. In 15 old-age institutions, the Qingshan District Social Welfare Institute, which belongs to the state-run old-age institutions, has a medical clinic. Three private old-age institutions, namely Wudong Puren Bailing Community Nursing Home, Shipyard Community Nursing Home and Baiyushan Community Nursing Home, implemented the model of combining medical and nursing care. The remaining 11 pension institutions currently have no medical services.

2) There is a need for community home service: At present, in accordance with the requirements of civil affairs in [2016] 11 text, it should do a good job of home care services for the poor elderly. And then, the government would purchase the socialization of nursing services. As a result of high standards and strict audit, only 68 poor elderly people enjoy free services, and 4 poor elderly people enjoy compensation services in this region. The service content mainly includes the meal service, the cleaning service, the assistance service, the escort service, the medical rehabilitation and the psychological support and so on; the service standards can be divided into three categories, i.e. living care, integrated home care and other living service requirements of the clients.

\section{B. Analogy Analysis of the Advantages and Disadvantages}

At present, the family pension is still the main way for the elderly in the region. Taking Xinqiao community of Xingouqiao Street in Qingshan district as an example, the total population of Xinqiao community is 10076 . And 2386 old people are over 60 years old, accounting for $23.67 \%$ of the total population. Xinqiao community is a typical serious aging community in Chinese districts. Of the 2,386 elderly people, 15 old people are provided for by institutions. 249 old people are provided for at home in the community. And 2,122 old people are provided for at home in the family, accounting for the majority of the elderly in the family. According to extensive investigation, the three pension models have their own advantages and limitations.

1) It is easy to provide for the aged in the family, but the burden is heavy: The family needs all kinds of economic resources to provide for the aged by the family. And its advantages are in line with the traditional culture and customs of China. It can greatly reduce the economic burden of the government. On the one hand, the family planning policy which has been implemented for many years has spawned a large number of "421" families. Under the current social pressure, some families have exhausted a large amount of savings. However, they are unable to support the expenses of clothing, food, housing and transportation of the four elderly in their old age, especially the high cost of medical treatment. On the other hand, the absence of traditional culture and the decline of social morality in China lead to the weakness of the traditional "filial piety" of pension responsibility. The traditional model of "raising children and preventing old age" has been unrealistic. With the increase of population mobility, more and more families have empty nesters. And the subsequent pension problems cannot be solved by this model.

2) The organizations provide professional pension for the aged, and there is more restrictions: The elderly go to all kinds of pension institutions. Their lives and care are provided by the pension institutions. The residential forms could be divided into old people's home, nursing homes, gerocomium, and so on. The advantage of this model is to provide more scientific, professional and centralized pension services, and to reduce the cost of the whole society. However, there are still many constraints. First, the majority of people are still affected by the old idea. They think that the nursing home is the place for homeless elderly people to go. Second, the old-age service facilities charge a higher fee. And the old people's payment ability is weak to some extent. Third, the number of old-age institutions is small, and the growth rate is slow. It seriously lacks the nursing home. Fourth, there is serious shortage of professional service staff in pension institutions. Most of them have not received systematic professional training. The overall quality is not high. It is difficult to meet the needs of the elderly.

3) Community pension is convenient and efficient, but the investment is insufficient: Community home-based oldage service refers to the elderly living in their own families or community. While continuing to be taken care of by family members, the community pension institutions or related organizations would undertake the work of caring the elderly. This model exists between family pension and 
social pension. It has strong flexibility and adaptability. On the one hand, the social pension can reduce the burden of family members. On the other hand, the elderly could live in their familiar environment. And it is in line with Chinese traditional pension habits. Also, the elderly would get the spiritual comfort. Therefore, in recent years, the community home care has been the focus of the services in city and district. However, according to the current situation, the municipal and district governments have invested heavily in the work of home-based care. There are still some practical problems in the operation, such as the model of communitybased care hardware facilities, the serious idle professional facilities, the single main provider of home-based care, the shortage of manpower and funds for community-based care, the lack of nursing and rehabilitation services, and so on.

\section{MAIN PROBlems EXISTING IN THE ELDERLY-CARE POLICY MODEL IN QINGSHAN DISTRICT}

There is a big gap between the service ability and service quality of the old-age service in Qingshan District and the huge demand and social expectation of the old-age service. Through comprehensive analysis, the author finds that the prominent problem is the main contradiction that restricts the quality and effect of the old-age service. It is mainly shown in the following aspects:

\section{A. The Pension Service System Has Not Been Fully Established}

At present, the establishment of the old-age service system in Qingshan District is still in its infancy. The proportion of public pension institutions, private pension institutions and the community home service isn't scientific or reasonable. It hasn't formed the situation of overall matching, operation and coordination. In particular, there is still a gap in the use of endowment resources, and the establishment of elderly life-related welfare, life care, health care, physical fitness, cultural education and legal services as the main content of supporting services. It has not yet formed a perfect and supporting service system.

\section{B. The Quality of Personnel in Pension Institutions Is Uneven}

At present, more than $80 \%$ of the private nursing homes in Qingshan District are laid-off workers or migrant workers. Few of them have received formal professional training. There are some volunteers. However, the volunteering is random. It cannot ensure the community's demand for the old-age service personnel.

\section{The Quality of Service Provided by the Elderly Pension Institutions Is Not Optimistic}

Due to the scarcity of resources of public pension institutions, private pension institutions emerge. At present, most private nursing homes in Qingshan District are equipped with idle rooms and old ones. And some of them use residences as nursing homes. Indoor furnishings are generally simple. There is little equipment. They lack the refrigeration and heating facilities, necessary monitoring or temporary relief equipment for the care of the elderly. Dietary situation is different. Some institutions have recipes. They have various daily foods. However, some institutions can only provide a bed. And they can only feed a mouth.

\section{The Supervision on Pension Institutions and Incentive Means Are Limited}

Due to the great demand of the pension market, the institutional pension demands of low-income and middleincome people are more urgent. With the constraints of the funds, it leads to the phenomenon of "black surname" and "black support" of nursing homes endlessly. There are too much hidden dangers of supervision. And the difficulty is too great. The low-income families have been accustomed to low-cost pension services. To ban the unlicensed pension institutions is difficult for the government. If the governments ban the low-cost pension services, they would face a large number of low-income elderly resettlement and stability work. At the same time, the incentives and supportiveness of the well-regulated and well-serviced pension institutions are not strong enough, which easily leads to an awkward situation with longer running hours and heavier burdens.

\section{E. The Community Home-based Pension Support Service Is Incomplete}

Community home old-age care is the most popular model for the elderly. The elderly enjoy a variety of services in the nearest place. At present, the community pension service is undertaken by the community. The government investment is limited. The expectation of the elderly in the community is high. And the supporting ability of the community is limited. It forms the problems that the community wants to serve, is difficult to serve and unable to afford the fees. The elderly meal, medical treatment and sports are three types of service items of the largest demand. However, to achieve a meal, a doctor and a venue are more difficult for the community. And the following is a higher risk of service.

\section{OVERVIEW of CURRENT PENSION POLICIES AT AlL LEVELS IN CHINA}

\section{A. The Central Level}

The report of the 18th National Congress of the Communist Party of China (CPC) pointed out: "The ageing issue involves political, economic, cultural and social life, and many other fields. And it is a major social issue related to the national economy and the people's livelihood and the long-term stability of the country". It firstly pointed out that we must "proactively respond to the aging of the population and vigorously develop the services and industries of the aging population." The report of the Nineteenth National Congress pointed out that it was necessary to "proactively respond to the aging of the population and build an old-age policy system and social environment to promote medical care." And then, it would accelerate the development of oldage businesses and industries. Thus, it can be seen that the development of social endowment programs and the 
establishment and improvement of the pension service system are major strategic plans for the increasingly severe population ageing situation in China, as well as a livelihood project that concerns the fundamental interests of the broad masses of the people. "Several Opinions of the State Council on Accelerating the Development of the Elderly Care Service Industry" (Guo Fa (2013) No. 35) clearly stated that the goal of the old-age care service was to be completed by 2020 with home-based support, community-based support, and institutional support, appropriate scale, urban and rural pension service system. The pension service products are more abundant. The market mechanism is continuously improved. And it could develop the pension service industry healthily. The main tasks of the retirement service include six aspects. It should plan and develop urban aged care service facilities, vigorously develop the home care service network, vigorously strengthen the construction of old-age care institutions, earnestly strengthen rural aged care services, prosper the elderly care consumer market, and actively promote medical and health services. On September 3, 2014, the Ministry of Finance and other four departments issued the "Notice on Doing a Good Job of Government in Purchasing Old-age Care Services" and deployed to accelerate the government's purchase of old-age care services. The notice made it clear that China would basically establish a relatively complete government by 2020 . The purchase of pension service system will promote the establishment of an old-age care service system with perfect functions, appropriate scale, and coverage in urban and rural areas.

\section{B. Provincial And Municipal Levels}

In recent years, Hubei Province successively promulgated "Opinions of the People's Government of Hubei Province on Accelerating the Development of Elderly Care Services Industry" and the "Opinions of Civil Affairs Department and other 10 departments on supporting the development of the pension service industry by the social forces." In 2016, the Ministry of Civil Affairs issued "Notice on accelerating the reform and innovation of the pension service system and mechanism", we further liberalized the market for pension services, stimulated the vitality of private pension institutions, and continued to meet the needs of diversified and multi-level old-age care services. In 2015, the Wuhan Municipal Bureau of Civil Affairs issued the "Guiding Opinions on Deepening the Development of the Aged Care Service Industry". It fully opened up the private pension service industry and further increased the support of social forces in the development of the pension service industry.

\section{EnLightenMent OF THE OLD-AGE PENSION Policy MODEL AT HOME AND ABROAD}

\section{A. Reference to Foreign Pension Practice}

Some European and American countries are affected by many factors, such as the support of economic strength. And their old-age care models mostly rely on "social pensions". For example, the United States implements the "Social Services Neighborhood Subsidy Program", emphasizing that the community needs to support families with elderly people. That is to say, it should provide formal services based on the communities. Especially, on-site services would enhance the elderly's ability to live in the family, and help and support the elderly to be able to live independently at home. In the UK, the issue of old-age care was included in the scope of community services as early as in the 1970s. The community would provide the elderly with life care (personal care, cleaning, shopping, etc.), material support (food supply, installation facilities, tax relief, etc.), psychological support (treatment, care, etc.) and overall care.

In Asian countries, based on the continuation of the traditional Eastern family concept, family pension still occupies the dominant position. For example, Singapore vigorously promotes "filial piety" and launches a series of allowance programs to encourage children to live with the elderly, advocates a stable family structure for three generations. And it is the first country in the world to enact legislation on "keeping parents". It uses legal means to make the children take responsibility for taking care of their parents. Japan promotes "filial piety for parents", supports and encourages cohabitation family pensions, and stipulates and implements a series of social security measures that are conducive to the promotion of family pensions. These include children's care for low-income seniors over the age of 70 and enjoy tax reductions. The government provides the special equipment required by the elderly in bed.

\section{B. Reference to the Practice of Domestic Old-age Care}

Some of the experiences accumulated by some domestic cities in coping with the practice of aging are worth learning. For example, Shanghai is the earliest place to enter an aging city. And the most typical approach is to use the government as the leading intermediary institution within the framework of the existing administrative system. Organizational implementation and service organization will be carried out in detail. The government will use the operating mechanism of purchasing services to provide care services for the elderly. The Gulou District of Nanjing City has taken the lead in creating a "home care service network for the elderly" and explores the implementation of the community home care model. Its greatest feature is the way the government purchases services, and entrusts the home-based care service network to the social organizations in the form of project entrustment. In addition to this, the Baibu Pavilion model of Wuhan city highlights and gives full play to the role of volunteers. Kunming model focuses on the enterprise.

\section{Inspiration from Advanced Experience at Home and Abroad}

Through research, the old-age care models implemented in various countries have their own characteristics. They have some common features in their actual operations. First, in terms of service targets, they are treated differently based on individual differences in the age, income, and health status of the elderly. And the services would be more flexible. Second, in terms of the content of the projects, it basically covers the aspects of life care, spiritual comfort, personal development, etc. And it has taken into full consideration the 
actual needs of the elderly. Finally, in the way of service provision, it combines paid services with monetary subsidies, and mobilizes a wide range of social forces to participate in pension services. The government, the family and society all play an important role in providing for the elderly.

\section{TO ACCELERATE THE CONSTRUCTION OF THE ELDERLY-CARE POLICY MODEL IN QINGSHAN DISTRICT}

It should consider some factors such as the economic strength, human resources, cultural traditions and affection, space, services, and demand of the elderly in Qingshan District. Drawing on advanced domestic and international experience, the district should build family-based, community-based, and professional pension service model. This model has the characteristics of diversification of service subjects, diversification of service methods, publicization of service objects, and professionalization of service teams.

\section{A. To Strengthen Guidance and Social Participation, To Establish and Improve Regional Supporting Mechanisms for Old-age Care Services}

1) To establish support and coordination mechanisms between government and society: The government is the manager of the pension service industry. In order to build an effective pension service system, it is necessary to strengthen the role of the government in guidance, regulation, support and safeguard. We should effectively change the concept. The government must transform from arranging public services to the support and management of social forces. In accordance with the principle of policy guidance, government support, social development and market promotion, within the framework of the provincial and municipal policies, it could formulate and form "The admittance, incentive and exit mechanism of social pension institution in Qingshan District". And then, it should gradually improve the socialization of openness, equality and standardization of the access system for pension services. It guides and supports social forces to participate in the development of the pension service industry in various forms such as investment, contracting, leasing, trusteeship and shareholding.

2) To plan and provide resources for elderly care services scientifically: According to the present situation and advantages of the Bureau of the Ministry of Endowment Resources in Qingshan District, "the space layout planning of the endowment facilities in Wuhan District" and "the space layout planning of the medical and health facilities in Wuhan District" should be connected. First, the construction of the home endowment service center (station) of the community should be accelerated. In accordance with the 12 specifications of one street, it should integrate nursing homes, health service centres, sports and leisure centres and other facilities, venues and other resources of the existing community. And then, it would promote medical, cultural, sports and other functions, covering all communities. The second is to build or lease a group of old-age care institutions. It could attract social resources and establish or lease pension institutions in places where the elderly are relatively concentrated. And these places must have short distance from residence, medical care, leisure and transportation. And then, it would maximize service effectiveness and achieve scientific coverage of pension functions. The third is to integrate diversified functions of public services. It could integrate resources; effectively strengthen coordination and cooperation among various government departments such as civil affairs, health facilities, labor and social security, and culture and sports. Combining the characteristics of the elderly in the community, it could establish comprehensive retirement service model of "medical support", "cultural pension" and "elderly education".

3) To establish a supervision mechanism for pension institutions that includes "risk assessment, risk identification, and risk prevention": The civil affairs department took the lead to participate in the formulation of mechanisms of risk assessment, risk identification, and risk prevention with public security firefighting, food and drug supervision, and health and medical care for the elderly care services in Qingshan District, focusing on standards supervision, qualification supervision, and safety supervision. The first is to focus on risk identification. The civil affairs department should be the main body. And it could conduct inspections with the departments of public security firefighting, medical and health, and food safety. They adopt regular inspections and occasional random inspections. And efforts have been made to find out that various management loopholes and systems have not been implemented. For instance, during the flood season, special inspections on house construction will be intensified. And special inspections on food hygiene will be carried out in the season of infectious diseases. It should accelerate the establishment of risk information base for pension institutions. At the same time, it strengthened the supervision of the annual review system. It should promote the experience of Shanghai and other places and establish an annual review system for pension institutions. We could organize experts in the industry to adopt a variety of methods to carry out comprehensive assessments for the pension institutions. For those who do not meet the required deadlines, obey or fail to meet the rectification requirements, we must take compulsory measures to withdraw, and properly place the elderly. It should give play to the supervision role of the public. And we should promulgate relevant methods to encourage the public to report complaints of violations of laws and regulations by the pension institutions. The second is to strengthen risk prevention. We will accelerate the standardization of oldage care institutions. The existing old-age care institutions should carry out the construction of demonstration old-age care institutions to promote the norms and the prevention of 
standards. It should support the brand pension institutions to export their management norms and standards, and achieve chain operations. Combining with the construction of smart cities, it should select qualified nursing homes to carry out trials on high-tech risk prevention. And then, we could gradually promote them. For example, there are emergency call buttons everywhere in the outdoors. Each old man has a positioning watch, and the duty room could track the position through GPS. Some apartments install infrared sensor device in the room. Once the elderly stay in a room for more than half an hour or an hour, the guardians will receive an alarm. It should strictly implement the administrative licensing system for pension institutions. For those old-age care institutions that have not obtained permission from the pension institutions, it should suspend business for rectification. And they are firmly responsible for illegal actions. The third is to enhance the ability to resist danger. It should introduce risk education in the cultivation of professional talents for aged care services. A special caregiver school was established to uniformly recruit and train nursing staff and distribute them to various nursing homes. We should accelerate vocational training, establish a corresponding practice base, encourage and attract college students to join institutional pension service, ensure highquality personnel supply, and form a linkage mechanism. It is necessary to strengthen learners' risk education, increase their sense of responsibility, and popularize common knowledge on fire fighting and rescue. And then, we could respond calmly to various crises. Leaded by the civil affairs department, the health and firefighting departments would regularly carry out joint drills. It is recommended to continuously improve the emergency management system for pension institutions, strengthen institutional mechanisms, increase emergency response drills and education training, and improve and standardize related emergency rescue procedures for elderly care organizations. And it would further enhance linkage handling capabilities.

4) To improve social assessment and recognition of pension professionals: Socialized old-age care services include life care, spiritual comfort, psychological adjustment, rehabilitation care, hospice care, and emergency relief. It is necessary to establish a service team that combines socialization and specialization. In the end, it would achieve the sustainable development of pension service. On the one hand, it is necessary to expand the introduction channels of service personnel. Combining with the employment of laid-off workers, rural migrant workers and re-employment projects, we could integrate human resources, promote, organize and guide volunteer activities, mobilize all types of personnel to participate in serving the elderly, and cultivate dedicated and part-time employee to service for the elderly. On the other hand, it is to improve the economic and social treatment of pension service professionals. It should strengthen the guiding role of the government, establish recognition and incentive mechanisms of excellent professional talent, explore the government subsidy system for pension service professionals, and improve economic treatment. At the same time, it should integrate the civil affairs, health, medical insurance qualification system and training resources, carry out vocational training for elderly care workers, improve employees' professional ethics, business skills and service quality.

\section{B. To Aim at the Demand, Integrate Resources and Improve Quality of Home Care Services of the Community}

1) To unify standards, integrate the elderly-care services into the overall planning of the community service system: With economic and social development, we should rely on the community and take care of the elderly. The medical rehabilitation and spiritual comfort would be the main content. The visiting service or day care of the community is the main form. And the home pension is combined with family endowment. And then, it formed the community pension service. And it has been the focus of the development of pension service system. We will improve the community-based, home-care service network. The enterprises, social organizations and other organizations should be the main body. And it could meet the service needs of all types of elderly people. We will implement the "9055" old-age service target put forward by the municipal government (i.e. 90 percent of the elderly are in home-based pension service. 5 percent of the elderly are in communitybased pension service. 5 percent of the elderly are in oldage-care institutions).

2) To integrate resources and broaden the connotation of community pension service: It should integrate community health, culture, sports, education and other industrial resources and social service resources such as housekeeping, property, food and beverage, logistics and convenience services. It should rely on community homebased care service centers and provide "helping meals, bathing, cleanliness, emergency services, entertainment and other customized services for senior citizens according to the needs of the elderly". It would include home visiting, spiritual comforts, community rehabilitation, legal advice, elderly universities, home security, and other threedimensional home services to enable older people to enjoy their lives in the community.

3) To strengthen the guidance and the consciousness of pension service at home: While focusing on improving the content and quality of home-based care services, we should encourage, guide the elderly and their supporters to actively guide the elderly groups to establish the concept of consumption of home-based care services through various public welfare cultural activities in the community. The pension mode of "active service of service provider - the dependence of the elderly - increase service frequency and expand service items - specialization of service" is formed. 
This mode has combined the effective demand of the aged with the guiding consumption of service provider.

4) To expand the new thinking and explore the "Internet $+"$ smart model of home-based elderly care: We should use modern "Internet +" and "Internet of Things". The enterprises, medical institutions and pension institutions should use Internet resources, big data, smart cloud, special networking and other technical means. The community elderly care groups should be the service object. We should collect and integrate the safety and health information of the elderly, and develop intelligent pension service platform. Professional medical and health service institutions, rehabilitation centers, and home service, first-aid services should be connected with individuals and families anytime and anywhere. It is to provide long-distance health monitoring, safety management, health management and life care services for the elderly.

\section{To Advocate Integration and Nurture Multiple Pension Services Industry}

1) Focusing on "the doctor", to develop the integration of medical care and pension services: The medical and nursing care institutions provide medical care, nursing care, rehabilitation, old-age care, and hospice care services. They provide services for the elderly, bedridden and advanced treatment. And it could solve the problems of not being able to support the elderly in the hospital and being unable to see a doctor in the nursing home. In the combination of medical care and health care, we must first establish a sound cooperation mechanism. We must encourage the medical and health institutions and the aged care institutions to carry out agreement and cooperation. And then, we would clarify the responsibilities. It would ensure that the senior citizens of the old-age care institutions receive medical treatment based on the principle of mutual benefit timely and effectively. The second is to encourage the pension institutions to set up medical institutions, realize medical insurance networking, and define the range of medical care combined projects and settlement methods. And it would appropriately increase the proportion of reimbursement for medical treatment and medical services. And it would provide certain economic support for the elderly to enjoy medical services. The third is to promote home visiting. The community health service center provides extended outpatient services such as family visits, emergency calls, home care, and family beds for the elderly at home.

2) Focusing on "elderly-learning" and nurturing education for the elderly and cultural integration: It is the most effective measure to satisfy the spiritual needs of the majority of elderly people through the development of elderly education and spiritual and cultural endowment. The first is to run schools for the elderly. The schools for the aged are an organization that integrates physicality, knowledge, and entertainment. In these schools, older people can reintegrate into the collective and learn their knowledge while enjoying life. The second is the mechanism of flexible community activities. We should provide necessary facilities, set up an amateur sports team for the elderly, and enrich the cultural life of the elderly and communicate the feelings of the neighborhood by actively organizing literary and artistic performances, sports fitness, knowledge lectures, psychological decompression and other activities. Third, we should set up mutual-help service organization for the elderly, give play to the role of helping the elderly, encourage them to participate in community voluntary service, and ask veteran comrades to speak about history, tradition, experience, heroic and exemplary deeds, preach Chinese virtues, and publicize the customs of civilization. Let them show their talent and value in volunteering.

3) Focusing on "living", to create a blend of commercial housing and pension functions: At present, the majority of the elderly people live in ordinary residential areas. The pension services facilities cannot meet the needs of the elderly. While reforming the old community, we should guide the powerful real estate enterprises to construct new type of old-age care community that truly meets the actual needs of the elderly. And we should reform the existing living environment, and establish the corresponding facilities such as medical care room, cultural activity station, health care hall, small garden and so on. And then, we can construct the ecological environment suitable for old-age care. It should release the pension service market. Through the awards and subsidy, project subsidies, etc., it should support social forces to invest in the aging industry, create favorable market development environment, and enrich oldage services and product supply.

\section{To Change Ideas, Advocate and Actively Create an Atmosphere of Respect for the Elderly}

1) Efforts should be made to cultivate a new trend of cultural pension: "Culture and old-age care" is a kind of old-age care that embodies traditional culture and contemporary humanistic care. It is based on the satisfaction of elderly people's guarantee of old-age care. On the one hand, it provides a good cultural environment and establishes an active concept of old-age care for the elderly. They would positively face their own old age. On the other hand, they build a platform for emotional communication, cultural fitness, learning and entertainment for the elderly. The first is to speed up the construction of social and cultural elderly service system integrating urban and rural areas. And it would increase the inclusiveness of cultural pensions. It should vigorously carry out "cultural poverty alleviation" and "minimum cultural protection", and mobilize social forces. From the government to the street communities, from old-age institutions to families, it should give full play to the enthusiasm of the country, society and individuals, enrich old-aged cultural activities, and organize regular activities. It should carry out scientific and healthy 
cultural and sports activities. These entertainment activities would enrich the spiritual and cultural life of the elderly. The second is to inspire the sense of participation of the elderly. We should guide them to integrate into the society and devote their remaining energy. It should enable the elderly to establish a positive concept of old-age care. They would positively face their own old age. And we should create conditions for the elderly, make them be out of their own closed space, go to the society, and integrate into the society. We could build the platform for emotional exchange, learning and entertainment, cultural and leisure activities for the elderly.

2) To promote the traditional culture of family pension: The newly revised "Law of the People's Republic of China on the Protection of Rights and Interests of the Elderly" clarifies the family and society's responsibility for old-age care, pays more attention to family pensions, and clarifies that the pension is "based on home-based care". Families need to give full play to their pension function and encourage children and parents to live nearby. On-the-job employees with senior citizens and sick elderly people are given paid holiday. And then, they can take care of the elderly at home. Government departments must increase the responsibility for family pensions and promote the traditional virtues of "good and filial piety". Through various forms, they will guide their children to perform filial piety, perform support duties, establish harmonious family relationships, and strengthen their children's statutory duties. This would lay the foundation for endowment services.

\section{CONCLUSION}

In short, the pension cause is sunrise industry concerned about the elderly. Good aging work is related to the wellbeing and sense of attainment of thousands of households. Governments at all levels and relevant departments must increase the top-level design, and improve the multi-level pension demand policy system. From the practical point of view, the needs of the elderly and the perspective of social harmony and stability, people would live and work in peace and contentment. And we should build more humanized pension policy model. It is consistent with the national situation. It is for tomorrow. Also, it is for us.

\section{REFERENCES}

[1] "Implementation of Document No. 35 by Hubei Province to Accelerate the Development of Pension Services Industry". Docin.

[2] Zhao Lihong. "Comparison of the status of old-age care in China and the West and its enlightenment." Academic Exchange. 2015

[3] Cai Liying. "Study on the construction of elderly care service system in urban community in Wuxi city". Master Thesis of Southeast University. 2013

[4] Wu Xiufang. "The role of the government in community pension services." Oriental Corporate Culture. 2014

[5] Yin Jie, Yan Juan. "Analysis of problems and countermeasures in government purchase of pension services". Reform and Opening. 2014
[6] Guo Jingcheng. "International comparison and reference of homebased care for the elderly". Social Security Research. 2010

[7] Chen Huixing. "Research on resource allocation of urban community based on elderly demand - Taking Xi'an as an example". Master Thesis of Xi'an International Studies University. 2015

[8] Sun Yan. "The socialization of retirement services: the practice model of tripartite cooperation among government, community and social organizations". China Science Periodical Database. 2010

[9] Kang Hongge. Creative research on China's endowment service model in the new era. Master Thesis of Tianjin University of Commerce. 2014 